\title{
PRODUÇÃO E CARACTERIZAÇÃO DE BIOFILMES DE AMIDO DE BATATA DOCE E CRUEIRA PLASTIFICADOS COM GLICEROL E SORBITOL*
}

\section{Resumo}

\author{
Ana Carolina dos Reis Lima ${ }^{1}$ \\ Brenda Samira Guimarães de Souza ${ }^{1}$ \\ Hárita da Silva Silva ${ }^{1}$ \\ Jéssica Sobrinho Lopes ${ }^{1}$ \\ Maricely Janette Uria Toro ${ }^{2}$ \\ Simone Yasue Simote Silva ${ }^{3}$
}

No presente artigo objetivou-se, principalmente, promover a síntese e caracterização de biofilmes ecológicos elaborados a partir do amido de batata doce e da crueira de mandioca, utilizando como plastificantes o glicerol e o sorbitol. O amido da batata doce foi obtido através de descascamento, trituração, filtração, decantação e secagem, respectivamente; enquanto a crueira de mandioca foi obtida por doação. Os biofilmes foram confeccionados na proporção de 3 gramas de amido/100 gramas de solução filmogênica, e 30 ou 40 \% de plastificante em relação à massa de amido, as soluções foram aquecidas e agitadas à $80^{\circ} \mathrm{C}$, depositadas em placas Petri, e secas em estufa à $50^{\circ} \mathrm{C}$ por 24 horas, e à temperatura ambiente. As amostras de biofilmes foram analisadas quanto aos aspectos visuais, solubilidade em água, teor de umidade, resistência química e Espectroscopia de Infravermelho por Transformada de Fourier (FTIR). Obteve-se 18,16\% de rendimento na extração do amido; solubilidade em água e teor de umidade variando, respectivamente, entre 0,03-0,12, e 2,79-11,812\%; os filmes mostraram-se insolúveis em clorofórmio, acetona e álcool; e as reações foram confirmadas através de Espectroscopia de Infravermelho por Transformada de Fourier.

Palavras-chave: Biofilmes; Amido; Batata doce; Crueira.

\section{PRODUCTION AND CHARACTERIZATION OF BIOFILMS OF SWEET POTATO STARCH AND GLOVER PLASTICATED WITH GLICEROL AND SORBITOL \\ Abstract}

In the present article the objective was to promote the synthesis and characterization of ecological biofilms made from sweet potato starch and manioc crunch, using glycerol and sorbitol as plasticizers. Sweet potato starch was obtained by debarking, grinding, filtration, decantation and drying, respectively; while the manioc crunch was obtained by donation. The biofilms were prepared in the ratio of 3 grams of starch / 100 grams of filmforming solution and 30 or $40 \%$ of plasticizer in relation to the starch mass, the solutions were heated and shaken at $80^{\circ} \mathrm{C}$, deposited in Petri dishes, and dried in an oven at $50^{\circ}$ $\mathrm{C}$ for 24 hours, and at room temperature. The biofilm samples were analyzed for visual aspects, water solubility, moisture content, chemical resistance and by Fourier Transform Infrared Spectroscopy (FTIR). 18.16\% yield was obtained on the extraction of the starch; solubility in water and moisture content varying, respectively, between 0.03-0.12 and 2.79-11.812\%; the films were insoluble in chloroform, acetone and alcohol; and the reactions were confirmed by Fourier Transform Infrared Spectroscopy

Keywords: Biofilms; Starch; Sweet potato; Crueira.

1 Discente do curso de Engenharia de Materiais, na Universidade Federal do Sul e Sudeste do Pará, Marabá, Pará, Brasil.

2 Docente do curso de Engenharia de Materiais, da Universidade Federal do Sul e Sudeste do Pará.

3 Docente do curso de Química, da Universidade Federal do Sul e Sudeste do Pará 


\section{INTRODUÇÃO}

A necessidade de produção em larga escala de embalagens duráveis, para utilização diária no mercado, fez com que os plásticos assumissem um papel de destaque em praticamente todos os seguimentos de produção. Neste cenário atual houve grande interesse na pesquisa e desenvolvimento de materiais de embalagem biodegradáveis com intuito de diminuir o acúmulo de resíduos plásticos no meio ambiente. Soares [1].

Segundo Silva [2], a utilização de plásticos sintéticos possui como principais características o baixo custo, fácil processamento, alta aplicabilidade e durabilidade, sendo essa última característica o fator de maior desvantagem para a sua utilização. Por ser um material hidrofóbico, o plástico não permite a ação microbiana, demorando centenas de anos para ser decomposto. Atualmente, tem-se procurado diferentes tipos de embalagens que protejam os alimentos da forma mais natural possível, sem prejudicar o meio ambiente. Uma das alternativas propostas é a substituição dos derivados de petróleo por novas matérias-primas como o amido, na forma dos denominados biofilmes.

Biofilmes são produzidos a partir de materiais biológicos, podendo agir como barreira a elementos externos e protegendo os produtos embalados de danos físicos e/ou biológicos, aumentando assim sua vida útil. Dentro deste contexto o amido é considerado um material promissor no desenvolvimento de bioembalagens. Mei [3].

O amido é a substância de reserva predominante em plantas. É formado primariamente por cadeias lineares e ramificadas de moléculas de glicose denominadas amilose e amilopectina, respectivamente. Ocorre na forma de grânulos que são relativamente densos e insolúveis, porém hidratam-se em água fria. Mei [3]. De acordo com Miranda [4], da batata doce pode ser extraído amido de alta qualidade, empregado na indústria de tecidos, papel, cosméticos, preparação de adesivos e glucose, e na manufatura de alimentos industrializados.

$\mathrm{Na}$ produção de farinha de mandioca o resíduo do peneiramento da massa é denominado crueira, material composto por fiapos, entrecascas e cepas que, após secagem, pode apresentar na sua composição em média $69 \%$ de amido; $15 \%$ de fibra bruta; $9,52 \%$ de umidade; $0,8 \%$ extrato etéreo; $0,7 \%$ de cinza e $0,7 \%$ de proteína bruta. Apesar de não existirem dados absolutos a respeito da quantidade total produzida deste resíduo, estima-se que cerca de $10 \%$ da mandioca utilizada na fabricação de farinha é eliminada na forma de crueira. Pereira [5].

Conforme Mali [6], os plastificantes reduzem as forças intermoleculares e aumentam a mobilidade das cadeias dos polímeros, com diminuição de possíveis descontinuidades e zonas quebradiças, resultando assim em materiais com menores temperaturas de transição vítrea (Tg). E ainda segundo Shimazu [7], os plastificantes devem ser compatíveis com o biopolímero e, os mais estudados em combinação com os filmes de amido são os polióis, como o glicerol e o sorbitol, materiais que interagem com as cadeias de amido, aumentando a mobilidade molecular e, consequentemente, a flexibilidade dos seus filmes.

Mali [8] e Omotoso [9] citam que o glicerol é um plastificante hidrofílico bastante empregado, que interage com as cadeias de amido tornando as moléculas de água disponíveis, assim aumentando a mobilidade molecular por meio da redução das ligações internas de hidrogênio entre as cadeias de polímero e, conseqüentemente, a hidrofilicidade e a flexibilidade dos filmes plastificados. Gomes [10] explica que o sorbitol tem como principais características o fato de ser capaz de produzir soluções viscosas e de grande aplicabilidade, principalmente na indústria de alimentos, 
farmacêutica e estética, também tem funções de plastificante como melhorador de processabilidade e promove o aumento da flexibilidade.

Como os filmes confeccionados exclusivamente por amido são pouco flexíveis e quebradiços e apresentam baixa maquinabilidade, ou seja, se adequam com dificuldade aos processamentos convencionais para a produção de embalagens, a introdução de aditivos às matrizes poliméricas é necessária. A questão da rigidez pode ser resolvida através da adição de plastificantes, que melhoram as propriedades mecânicas dos filmes. Shimazu [7].

A aplicação do amido na confecção de biofilmes se baseia nas propriedades químicas, físicas e funcionais da amilose para formar géis e na sua capacidade para formar filmes. Shimazu [7]

Diante disto, os objetivos do presente trabalho foram promover a síntese e caracterização de biofilmes ecológicos elaborados a partir do amido de batata doce e da crueira de mandioca, utilizando como plastificantes o glicerol e o sorbitol, e caracterizando-os quanto aos aspectos visuais e táteis; solubilidade em água; teor de umidade; resistência química em contato com clorofórmio, acetona e álcool etílico; e através de espectroscopia de infravermelho.

\section{MATERIAIS E MÉTODOS}

\subsection{Obtenção do amido de batata doce e crueira}

A obtenção do amido de batata doce foi realizada através de algumas adaptações da metodologia seguida por Silva [2]. Primeiramente foi removida toda a casca das batatas, seguida de lavagem, e trituração em raladores. Em seguida, a massa triturada obtida foi transferida para um recipiente (bécker $2 \mathrm{~L}$ ) com adição de água destilada (1 $\mathrm{kg}$ de massa triturada/1,5 $\mathrm{L}$ de água destilada) em temperatura ambiente e agitação manual. Assim, o material obtido foi filtrado em peneiras (Mesh Tyler 14, 16, 48 e 100, respectivamente); a seguir o permeado contendo amido foi transferido para recipiente e mantido sob refrigeração por 24 horas, para ser promovida a separação das fases por decantação. A fase precipitada (amido) foi submetida à secagem em estufa à $60^{\circ} \mathrm{C}$ por 24 horas.

A crueira utilizada foi doada por empresa manufatureira da cidade de Belém, no Estado do Pará.

\subsection{Preparo dos biofilmes}

A metodologia empregada consiste de uma adaptação de Gomes [10]. Os biofilmes foram confeccionados com amido de batata doce e crueira, na proporção de 3 gramas de amido/100 gramas de solução filmogênica, e empregando-se dois tipos diferentes de plastificantes (sorbitol e/ou glicerol) em diferentes concentrações prédefinidas de acordo com a massa de amido utilizada (30 e $40 \%$ de plastificante). As soluções contendo amido e água foram agitadas e aquecidas em banho-maria à $80^{\circ} \mathrm{C}$ por 15 minutos, adicionado o plastificante e progrediu-se aquecimento e agitação por mais 2 minutos.

Em seguida, foram transferidos $20 \mathrm{~mL}$ de cada solução filmogênica para placas Petri. Algumas amostras foram secas em estufa à $50^{\circ} \mathrm{C}$ por 24 horas, e outras em capela à temperatura ambiente.

\subsection{Caracterização dos biofilmes}

\subsubsection{Aspecto visual}


Segundo Arenas [11], refere-se à aparência do filme avaliada por observações táteis e visuais. O filme deve apresentar uma superfície homogênea e contínua, ou seja, devem ser excluídos das análises aqueles filmes defeituosos que apresentaram fissuras e bolhas após o processo de secagem, ou aqueles que continham partículas insolúveis ou poros abertos.

Após a secagem dos filmes de batata doce e crueira elaborados, foram realizadas análises considerando os aspectos táteis e visuais para escolha dos melhores.

\subsubsection{Solubilidade em água}

A análise de solubilidade em água dos filmes foi feita com base em adaptação do método proposto por Gontard [12]. Inicialmente, pequenas seções dos filmes foram obtidas, secas em estufa à 100, pesados e então imersos em água destilada, mantidos sob agitação manual lenta e periódica à temperatura ambiente. Os fragmentos de filme restantes foram então retirados do banho e secos em estufa à $100^{\circ}$ para determinação da massa seca final dos mesmos. O cálculo para solubilidade foi realizado conforme a equação 1:

$$
\mathrm{pm}=\frac{\mathrm{mi}-\mathrm{mf}}{\mathrm{mi}}
$$

Onde, pm refere-se à perda da massa, mi é a massa inicial obtida na primeira pesagem e mf é a massa final.

\subsubsection{Determinação da umidade do biofilme}

Similarmente Silva [2], para a determinação da umidade do biofilme as amostras foram previamente pesadas e inseridas em estufa à $100^{\circ} \mathrm{C}$. A umidade foi obtida pela equação 2 :

$$
\mathrm{h}=\frac{(\mathrm{mi}-\mathrm{mf})}{\mathrm{mi}} * 100 \%
$$

Onde h é o percentual da umidade, mi a massa inicial pesada e mf a massa final após o período de secagem.

\subsubsection{Resistência química dos biofilmes}

Para avaliação da resistência química, pequenos fragmentos foram depositados em tubos de ensaio previamente identificados, e em seguida, imersos em clorofórmio, acetona e álcool etílico.

\subsubsection{Espectroscopia no Infravermelho por Transformada de Fourrier}

Pequenos fragmentos de biofilmes referentes à cada formulação foram analisados em Espectrofotômetro no Infravermelho por Transformada de Fourrier (FTIR) (Cary 630 da Agilent com o acessório ATR de diamante). Os espectros foram obtidos na faixa de número de onda de 4000 a $650 \mathrm{~cm}^{-1}$, e as bandas de vibração foram associadas aos principais grupos químicos.

\section{RESULTADOS E DISCUSSÃO}

Visto que, no processo de extração do amido de batata doce, obteve-se rendimento de $18,16 \%$ de amido em relação à massa de batata doce triturada usada para a extração, e considerando que outras fontes de amido apresentam rendimento 
similar, como a batata inglesa (18\%), inhame (18-23\%) e mandioquinha salsa (5$23 \%$ ), conforme Silva [2]; e rendimento próximo ao da mandioca (22-27\%), de acordo com Silva [2], e ainda que o rendimento obtido está de acordo com Miranda [4] no qual pode ser obtido entre 13,4 a $29,2 \%$ de amido, pode-se afirmar que a batata doce pode ser utilizada para obtenção de amido pela indústria de alimentos.

Por intermédio da metodologia empregada para o preparo dos filmes (tópico 2.2), foram obtidos filmes de amido de batata doce e crueira, como mostra a figura 1:

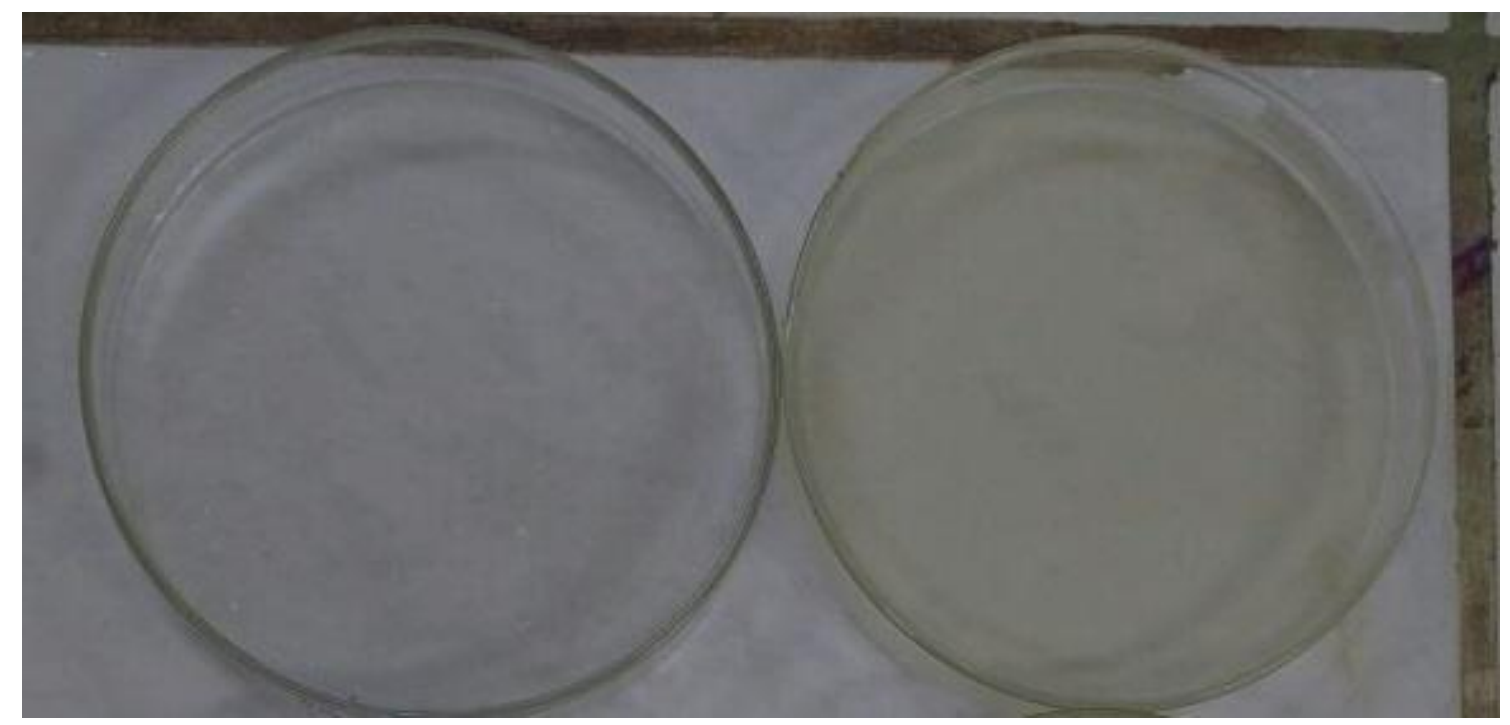

Figura 1 - Filmes de amido de batata doce (à esquerda) e crueira (à direita) em placas Petri

Fonte: Autores

É notável a diferença de coloração entre os filmes obtidos utilizando o amido de batata doce, que se mostraram mais incolores, e utilizando a crueira, os quais adquiriram uma coloração levemente amarelada. Resultados parecidos foram obtidos por Machado [13], onde as amostras de filmes contendo 4,2\% de amido de mandioca e $0,6 \%$ de bagaço de cevada, assim como as amostras contendo $4,8 \%$ de amido de mandioca e $0,4 \%$ de bagaço de cevada, apresentaram coloração amarelada pós-cura. Além disso, foi observado que os filmes apresentaram-se homogêneos, isto é, ausência de partículas insolúveis, bolhas visíveis a olho nu, zonas de opacidade ou de cores diferenciadas. $\mathrm{O}$ aspecto visual dos filmes não foi afetado pelos diferentes tipos de plastificante.

Dentre as formulações preparadas, todas aquelas que continham $30 \%$ de plastificante em relação ao amido foram descartadas, pois as amostras não apresentaram condições de serem analisadas em razão da pouca manuseabilidade dos filmes, isto ocorreu devido estes filmes mostrarem-se mais aderidos às placas Petri, assim houve dificuldade de removê-los sem danificá-los. Esta aderência pode ter ocorrido devido ao à proporção de plastificante:amido empregada nestas formulações, o que pode conferir uma maior adesividade às amostras. Shimazu [7] relata resultados em sua pesquisa para filmes de amido de mandioca, onde os filmes contendo $0,5,15$, e $30 \%$ de plastificante em relação ao amido apresentaram excelente ou boa manuseabilidade, porém os filmes com $40 \%$ exibiram o efeito de adesividade. Em contraposição, nos filmes realizados neste trabalho obtidos com batata doce e crueira, foram observados melhores resultados táteis e visuais nas amostras contendo $40 \%$ de plastificante. Além disso, foram observados melhores resultados para os biofilmes listados na Tabela 1: 
Tabela 1 - Identificação dos filmes de amido de batata doce e crueira com $40 \%$ de plastificantes Identificação Formulação

B1e

B2e

C1c

$\mathrm{C} 2 \mathrm{c}$

$\mathrm{C} 2 \mathrm{e}$

C3c
Amido de batata doce plastificado com $40 \%$ de glicerol curado em estufa

Amido de batata doce plastificado com $40 \%$ de sorbitol curado em estufa

Crueira plastificado com $40 \%$ de glicerol curado à temperatura ambiente

Crueira plastificado com $40 \%$ de sorbitol curado à temperatura ambiente Crueira plastificado com $40 \%$ de sorbitol curado em estufa

Crueira plastificado com $20 \%$ de glicerol e $20 \%$ de sorbitol curado à temperatura ambiente

Fonte: Autor

Quanto à solubilidade dos biofilmes em água, os resultados obtidos foram os seguintes: 0,12 para as amostras B1e; 0,10 para as amostras B2e; 0,05 para as amostras C1c; 0,09 para as amostras C2c; 0,04 para as amostras C2e; e 0,03 para as amostras $\mathrm{C} 3 \mathrm{c}$. Os quais foram inferiores aos resultados obtidos para os biofilmes de amido de pinhão elaborados por Silva [2], nos quais a solubilidade em água corresponde a $0,187 \pm 0,004$. Foi observado também que os biofilmes elaborados com amido de batata doce apresentaram maior solubilidade que aqueles compostos por crueira de mandioca, o que pode indicar que estes últimos são mais resistentes à solubilização em água, apresentando características menos hidrofílicas em relação aos que continham amido de batata doce. Mehyar [16] na análise de filmes de amido de ervilha e de arroz constata que os filmes de amido de ervilha geraram maior resistência à agua que os filmes de amido de arroz, e sugere que no caso do amido de ervilha (10\% a mais de amilose) o aumento da força intermolecular destes polissacarídeos poderia ter sido causado pela maior interação entre as moléculas de amilose, o que, por hipótese, é o principal mecanismo de formação de filmes de amido. Este fato pode também ter ocorrido, porém em menor intensidade, no caso dos filmes de batata doce e crueira elaborados neste trabalho, visto que o teor de amilose na crueira (segundo Pereira [5], 20\%) pode ser até 3\% superior ao apresentado pelo amido de batata doce (17,2 - 19,19\% de acordo com Gonçalves [17]).

Através da análise do teor de umidade dos biofilmes, foram obtidos os seguintes resultados: $11,81 \%$ para as amostras $\mathrm{B} 1 \mathrm{e} ; 10,44 \%$ para as amostras $\mathrm{B} 2 \mathrm{e} ; 4,60 \%$ para as amostras C1c; $9,20 \%$ para as amostras C2c; 4,34\% para as amostras C2e; e 2,79\% para as amostras C3c. De acordo com Dantas [15], a umidade corresponde à perda em peso sofrida pelo produto quando aquecido em condições nas quais a água é removida e outras substâncias se volatilizam. Os resultados das amostras B1e e B2e foram próximos do teor de umidade encontrado por Silva [2] em filmes de amido de pinhão (10,8 $\pm 0,4 \%)$; ainda segundo Silva [2] esse valor é aceitável para biofilmes, visto que para o biofilme apresentar boas propriedades de barreira, 0 mesmo deve apresentar umidade máxima de $10 \%$. Considerando esse pressuposto, todos os filmes, com exceção do B1e, obtiveram resultados satisfatórios. O teor de umidade de todas as amostras analisadas foram inferiores aos obtidos por Machado [13], que ao analisar amostras de filmes de amido de mandioca e bagaço de cevada obteve teores variando entre 14,51 e $22,72 \%$. Quanto à esta propriedade outro fator 
importante observado foi que a composição do filme e as condições de cura influenciaram na umidade dos biofilmes, nota-se que aqueles elaborados com amido de batata doce e glicerol apresentaram teores maiores que os plastificados com sorbitol, isto pode ter ocorrido em razão de o glicerol ser um plastificante hidrofílico, isto é, o glicerol pode ter promovido interações com as cadeias de amido, assim reduzindo as forças intermoleculares, aumentando a mobilidade entre as cadeias, e como consequência, a hidrofilidade dos biofilmes; ainda foi observado umidade mais elevada nas amostras elaboradas com crueira e sorbitol curados à temperatura ambiente em relação aquelas curadas na estufa, tal fato pode ser atribuído às condições de cura, salvo que a cura por temperatura permite a volatização mais eficiente tanto de moléculas de água quanto de substâncias voláteis presentes nos biofilmes, enquanto a cura à temperatura ambiente não permite a ocorrência adequada desta volatização; e que os biofilmes de crueira de mandioca e plastificados com $20 \%$ de glicerol e $20 \%$ de sorbitol curados à temperatura ambiente apresentaram menor umidade, tanto em relação às demais amostras de crueira quanto aquelas contendo amido de batata doce, isso indica que ambos plastificantes interagiram positivamente.

Em relação à análise da resistência química, de cada formulação dos biofilmes, foi observado que todas as amostras submetidas ao contato com os reagentes se mostraram inalteradas. E ainda que todas as amostras submetidas à análise em clorofórmio se apresentaram menos densas que este. $O$ fato de as amostras analisadas exibirem-se inalteradas indica a insolubilidade em contato com os diferentes solventes usados, e ainda, segundo Hernandez [14], pode ter havido formação de ligações cruzadas, uma vez que a fração reticulada do polímero é insolúvel. Hernandez [14] obteve resultados semelhantes ao testar a resistência química de biopolímeros sintetizados a partir de óleo de mamona em clorofórmio, acetona, etanol e THF, onde todas as amostras apresentaram-se insolúveis em contato com os solventes.

Os espectros de espectroscopia de infravermelho dos filmes da batata doce e crueira estão apresentados nas figuras 2 a 7, para cada formulação analisada:

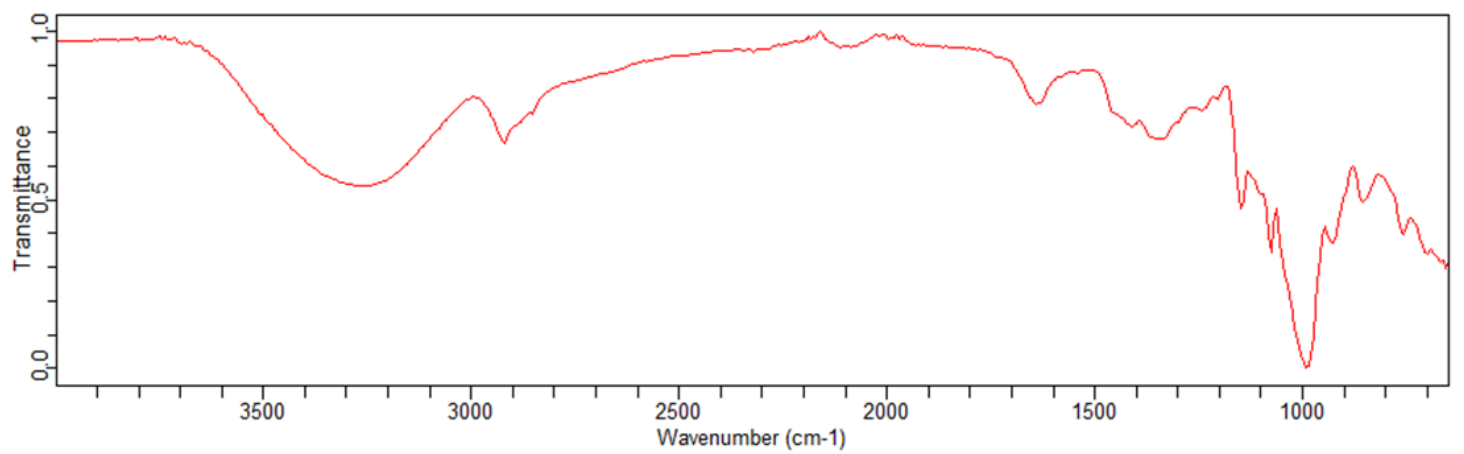

Figura 2 - Espectro da amostra de biofilme de amido de batata doce plastificado com $40 \%$ de glicerol curado em estufa

Fonte: Autores 


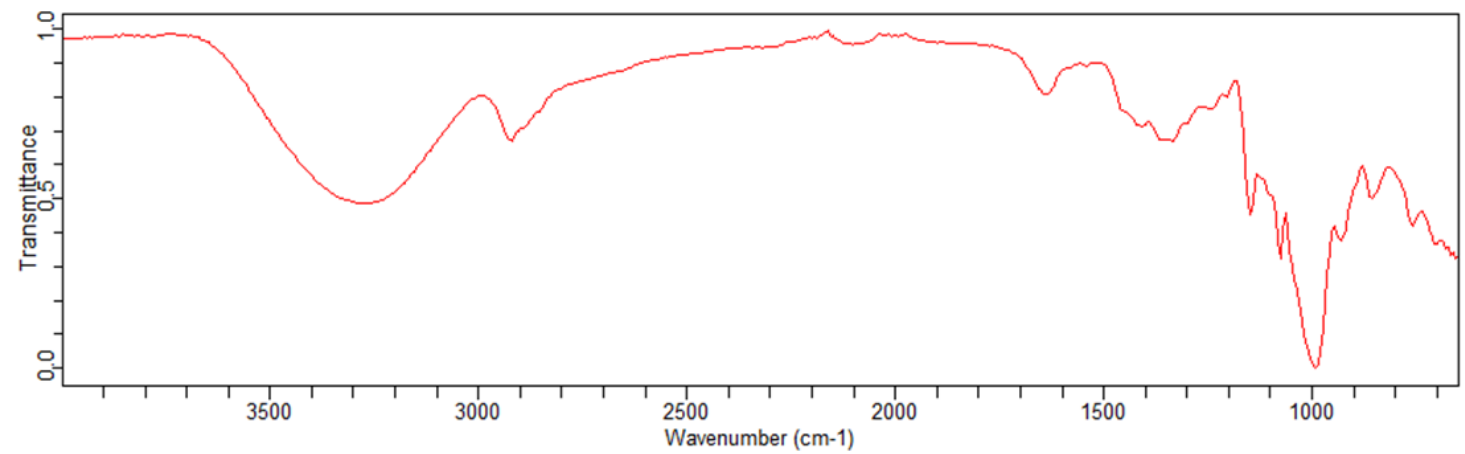

Figura 3 - Espectro da amostra de biofilme de amido de batata doce plastificado com $40 \%$ de sorbitol curado em estufa (B1e)

Fonte: Autores

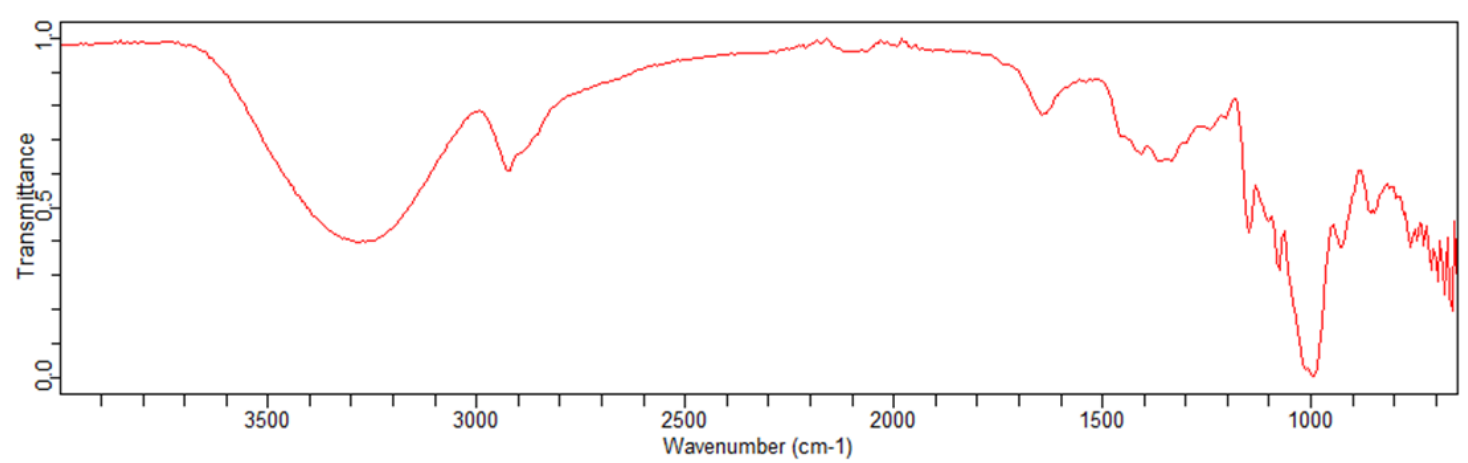

Figura 4 - Espectro da amostra de biofilme de crueira plastificado com $40 \%$ de glicerol curado à temperatura ambiente $(\mathrm{C} 1 \mathrm{c})$

Fonte: Autores

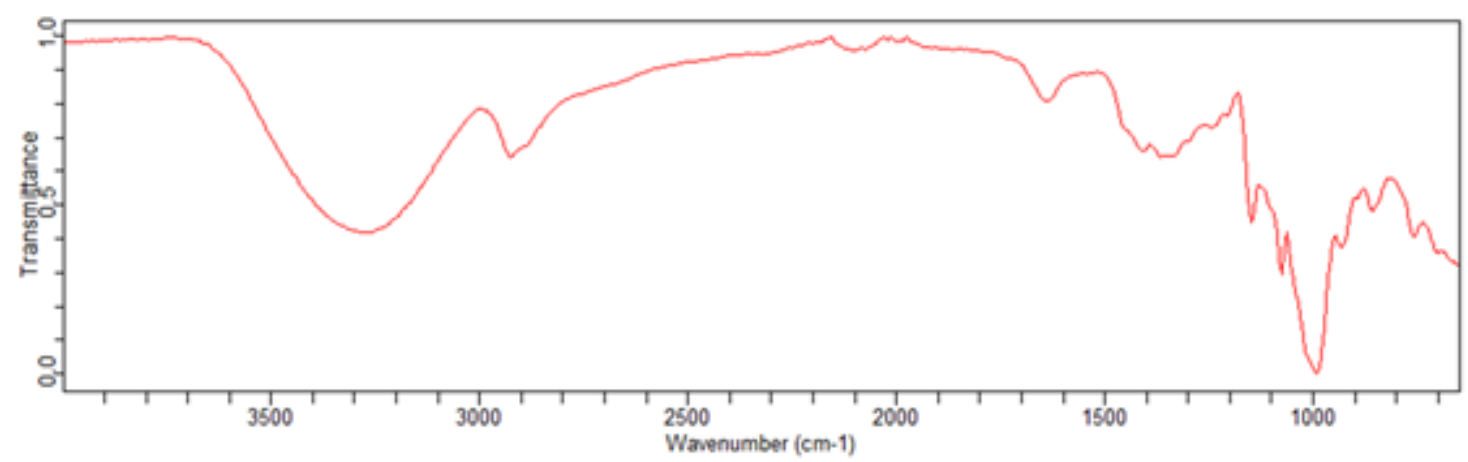

Figura 5 - Espectro da amostra de biofilme de crueira plastificado com $40 \%$ de sorbitol curado à temperatura ambiente (C2c)

Fonte: Autores

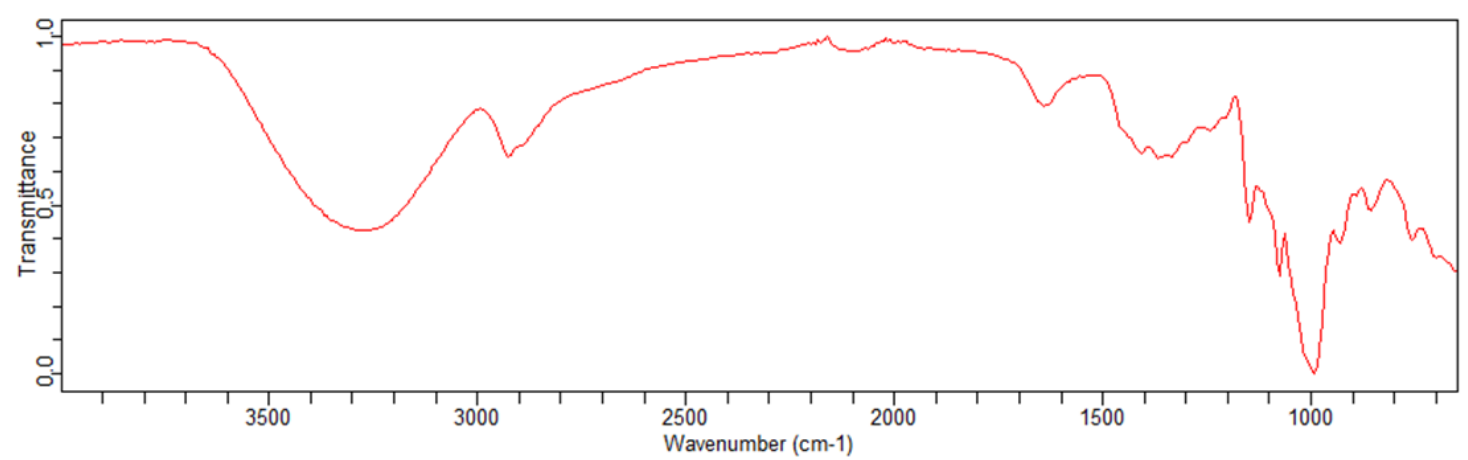

Figura 6 - Espectro da amostra de biofilme de crueira plastificado com $40 \%$ de sorbitol curado em estufa (C2e) 
Fonte: Autores

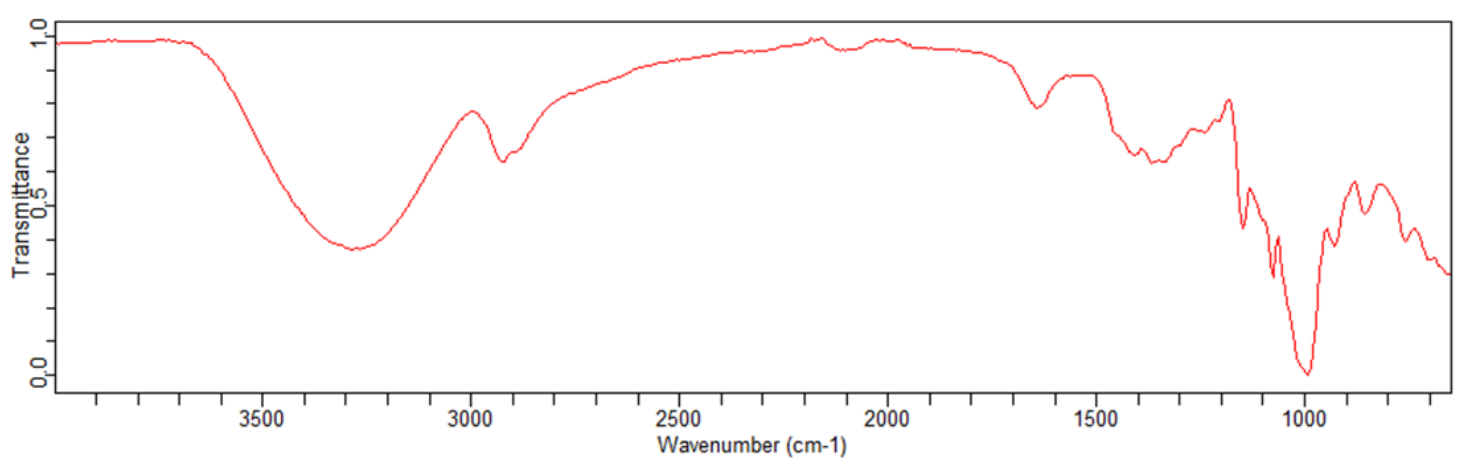

Figura 7 - Espectro da amostra de biofilme de crueira plastificado com $20 \%$ de glicerol e $20 \%$ de sorbitol curado à temperatura ambiente (C3c)

Fonte: Autores

Através da observação dos resultados obtidos é notável que as 6 amostras analisadas apresentaram espectros semelhantes, evidenciando assim que não houve diferenciação significativa entre as formulações elaboradas. Tal fato pode ser explicado em função dos filmes conterem os mesmos componentes principais (plastificantes e amido contendo amilose e amilopectina) e grupos funcionais semelhantes. Esse fato também foi observado por Machado [13] na análise de espectros de filmes biodegradáveis à base de amido de mandioca e bagaço de cevada, e por Dantas [15] na análise de espectros de biofilmes de amido de inhame, sendo que os filmes desenvolvidos por Machado [13] apresentaram espectros de absorção semelhantes ao obtido para as amostras de biofilmes de batata doce e crueira. Os espectros dos filmes apresentaram 5 bandas de absorção importantes: em torno de 3400 - $3200 \mathrm{~cm}^{-1}$ correspondendo à absorção associada às vibrações de deformação axial nos átomos de hidrogênio ligados a carbono, isto é, dos grupos hidroxila; as bandas de absorção entre 2800 e $3000 \mathrm{~cm}^{-1}$ indicam a presença de ligações $\mathrm{C}-\mathrm{H}$ alifáticos, ou mais precisamente, a ocorrência de estiramento do grupamento $\mathrm{CH}_{2}$ ou $\mathrm{CH}_{3}$; entre 1600 e $1700 \mathrm{~cm}^{-1}$ são apresentadas as bandas correspondentes à $\mathrm{C}=\mathrm{C}$; em torno de 1250 a $1500 \mathrm{~cm}^{-1}$ são notáveis as bandas referentes ao dobramento do grupo $\mathrm{CH}_{2}$; e em aproximadamente $1000 \mathrm{~cm}^{-1} \mathrm{o}$ espectro mostra picos intensos atribuídos à deformação angular fora do plano das ligações entre $\mathrm{CH}=\mathrm{CH}_{2}$. Considerando que as estruturas químicas, na literatura, das moléculas de sorbitol apresentam como principais grupos funcionais as hidroxilas, C$\mathrm{O}$ e $\mathrm{CH}_{3}$; que as moléculas de amido apresentam hidroxilas, $\mathrm{C}-\mathrm{H}, \mathrm{C}-\mathrm{O}$ e $\mathrm{CH}_{2}$; e as moléculas de glicerol também apresentam hidroxilas, $\mathrm{C}-\mathrm{O}$ e $\mathrm{CH}_{2}$; nota-se que a presença das bandas referentes às ligações duplas entre carbonos $\mathrm{C}=\mathrm{C}$ e $\mathrm{CH}=\mathrm{CH}_{2}$; e o não surgimento de bandas referentes às ligações $\mathrm{C}-\mathrm{O}$ e $\mathrm{C}-\mathrm{H}$, correspondem às bandas características de que a síntese dos biofilmes foi efetivada.

\section{CONCLUSÃO}

Por conseguinte, em virtude do rendimento de amido obtido no processo de extração apresentar resultado satisfatório, pode-se sugerir que a batata doce pode ser utilizada para obtenção de amido. O aspecto visual dos filmes foi afetado pelo tipo de amido, adquirindo coloração levemente amarelada quando utilizada a crueira, porém não houve mudança significativa nos aspectos táteis. Melhores resultados na 
elaboração dos filmes foram obtidos nas amostras contendo $40 \%$ de plastificante independente do tipo de amido utilizado na formulação.

\section{REFERÊNCIAS}

1 Soares IFO, Fakhouri FM, Giraldi ALFM, Buontempo RC. Síntese e caracterização de biofilme de amido plastificado com glicerol ou triacetina. Foco. 2014 jul-dez; 5 (7): 79-98.

2 Silva, E. Produção e caracterização de filmes biodegradáveis de amido de pinhão [Trabalho de diplomação]. Porto Alegre: Universidade Federal do Rio Grande do Sul; 2011.

3 Mei LHI. Bioplásticos: biodegradáveis \& biobased - definições, fontes e aplicações. Campinas: Unicamp; 2016.

4 Miranda JEC, França FH, Carrijo AO, Souza AF, Pereira W, Lopes CA. Batatadoce (Ipomoea batatas (L.) LAM). Circular técnica do CNPHortaliças 1989; 2 (3): 5-19.

5 Pereira G. Substituição do milho por farinha de crueira de mandioca (Manihot esculenta, Crantz) em rações para juvenis de tambaqui (Colossoma macropomum Cuvier, 1818) [Tese de doutorado]. Manaus: Universidade Federal do amazonas; 2011.

6 Mali S, Grossmann MVE, Yamashita F. Filmes de amido: produção, propriedades e potencial de utilização. Semina: Ciências Agrárias. 2010 janmar; 31 (1): 137 - 155.

7 Shimazu AA, Mali S, Grossmann MVE. Efeitos plastificante e antiplastificante do glicerol e do sorbitol em filmes biodegradáveis de amido de mandioca. Semina: Ciências Agrárias. 2007 jan-mar; 28 (1): 79 - 88.

8 Mali S, Grossmann MVE, García MA, Martino MM, Zaritzy NE. Barrier, mechanical and optical properties of plasticized yam starch films. Carbohydrate Polymers. 2004; 56: 129-135.

9 Omotoso MA, Adeyefa OS, Animashaun EA, Osibanjo OO. Biogradable Starch Film from Cassava, Corn, Potato and Yam. Chemistry and materials research. 2015; 7 (12): $15-24$.

10 Gomes, A. Avaliação do efeito do sorbitol e do glicerol nas características físicas, térmicas e mecânicas da película e do hidrogel de amido de milho reticulado com glutaraldeído [Trabalho de conclusão de curso]. Campo Mourão: Universidade Tecnológica Federal do Paraná; 2014.

11 Arenas AMZ. Filme biodegradável à base de fécula de mandioca como potencial indicador de mudança de pH [Dissertação de mestrado]. São Paulo: Escola Politécnica da Politécnica da Universidade de São Paulo; 2012.

12 Gontard N, Guilbert S, Cuq JL. Water and glycerol as plasticizers affect mechanical and water vapor barrier properties of an edible wheat gluten film. Journal of Food Science. 1993; 58 (1):206-211.

13 Machado TR. Elaboração e avaliação de filmes biodegradáveis a base de amido de mandioca e bagaço de cevada [Trabalho de conclusão de curso]. Anápolis: Universidade estadual do Goiás; 2013.

14 Hernandez NLP. Síntese de biopolímeros a partir de óleo de mamona para aplicações médicas [Tese de doutorado]. Campinas: Universidade Estadual de Campinas; 2015. 
15 Dantas RL. Extração e caracterização de amido de inhame para produção de biofilmes [Trabalho de conclusão de curso]. Campina Grande: Universidade Estadual da Paraíba; 2014.

16 Mehyar GF, Han JH. Physical and mechanical properties of high-amilose rice and pea starch filmes as affected by relative humidity and plasticizer. Journal of Food Science. 2004; 69: 449-454.

17 Gonçalves MFV, Sarmento SBS, Dias CTS, Marquezini N. Tratamento térmico do amido de batata-doce (Ipomoea batatas L.) sob baixa umidade em microondas. Ciência e Tecnologia de Alimentos. 2009; 29 (2): 270-276. 